\title{
ANALISA PENGETAHUAN IBU TENTANG TUMBUH KEMBANG BALITA DENGAN PARTISIPASI PENIMBANGAN BALITA DI POSYANDU ANGGREK KELURAHAN POPONGAN KABUPATEN SEMARANG
}

\author{
Widyah Setiyowati ${ }^{1}$, Titik Kurniawati ${ }^{2}$, Akhid Suraiya ${ }^{3}$ \\ 1,2,3 Akademi Kebidanan Abdi Husada
}

\begin{abstract}
Increased community participation at the village level and community families, especially in the development of maternal, child and family health which are priorities for health development through the Village Community Health Development approach, which is manifested in the form of developing and fostering posyandu, and so on. Posyandu is one of the supporting faktors indispensable for monitoring the growth of their children. The purpose of this study was to analyze the relationship between maternal knowledge about toddler growth and development with participation in weighing children under five at Posyandu Anggrek, Popongan Village, Semarang Regency. This type of research is a correlative study with a cross sectional approach. The population in this study were all mothers who had toddlers at the Posyandu Anggrek, Popongan Village, Semarang Regency, as many as 59 samples of women who obtained 37 respondents. The results showed that most of the knowledge of mothers under five is in the good category, namely 34 respondents $(91.9 \%)$. Most of the participation of mothers to come to the posyandu is in the participation category, namely 27 respondents (73.0\%). There is a significant relationship between the level of maternal knowledge about toddler growth and development with participation in weighing children under five at the Posyandu Anggrek, Popongan Village, Semarang Regency with a $p$ value of 0.798 ( $p>0.05$ ). Suggestions to the community, especially mothers and families with toddlers to always be active in visiting to the posyandu so that growth and development can be monitored..
\end{abstract}

Keywords : Knowledge; Participation; Posyandu 


\section{PENDAHULUAN}

Pembangunan kesehatan bertujuan untuk meningkatkan kesadaran, kemampuan dan kemauan untuk hidup sehat bagi setiap orang agar terwujud derajat kesehatan masyarakat yang optimal (Depkes RI, 2004). Pada masa anak dibawah 5 tahun kecepatan pertumbhan mulai menurun dan terdapat kemajuan dalam perkembangan motoric kasar dan halus serta fungsi sekresi (Marmi, Raharjo 2015). Periode penting dalam tahap ini akan mempengaruhi dan menetukan perkembangan anak selanjunya..

Masa balita merupakan periode penting dalam proses tumbuh kembang manusia. Perkembangan dan pertumbuhan di masa itu menjadi penentu keberhasilan dan perkembangan anak di periode selanjutnya. (Setyawati, Hartini 2018)..

Pengetahuan ibu tentang tumbuh kembang merupakan salah satu pendukung yang sangat penting untuk meningkatkan peran serta orang tua dalam meningkatkan kualitas hidup anak. Pengetahuan merupakan domain yang sangat penting dalam membentuk tindakan seseorang (Notoatmodjo, 2003).

Peningkatan peran serta masyarakat ditingkat desa dan keluarga masyarakat, khususnya pembinaan kesehatan ibu, anak, dan keluarga yang menjadi prioritas pembangunan kesehatan melalui pendekatan Pembangunan Kesehatan
Masyarakat Desa (PKMD), yaitu diwujudkan dalam bentuk pengembangan dan pembinaan posyandu, dan sebagainya (Depkes RI, 2004).

Posyandu adalah kegiatan kesehatan dasar yang diselenggarakan dari, oleh dan untuk masyarakat yang dibantu oleh petugas kesehatan di suatu wilayah kerja Puskesmas, dimana program ini dapat dilaksanakan di balai dusun, balai kelurahan, maupun tempat-tempat lain yang mudah didatangi oleh masyarakat (Sulistyorini, 2010).

Partisipasi ibu balita dalam kegiatan posyandu merupakan salah satu faktor pendukung yang sangat diperlukan untuk pemantauan pertumbuhan anaknya.

Pengetahuan ibu balita untuk menyadari bahwa posyandu merupakan hal yang utama untuk meningkatkan derajat kesehatan balita, sehingga dapat menimbulkan perilaku positif ibu balita tentang posyandu. Pengetahuan ibu balita yang positif akan mempengaruhi perubahan perilaku yang positif (Arali, 2008)

Berdasarkan data posyandu di Dusun Popongan Kelurahan Popongan Kabupaten Semarang pada bulan Februari 2020 terdapat 59 balita, sedangkan yang menimbang ke posyandu tiap bulan rata-rata 45 balita (50,56\%). Sebagian ibu beranggapan bahwa anaknya dalam kondisi sehat, posyandu hanya tempat untuk menimbang bukan untuk memantau tumbuh kembang. 
Dari data tersebut, maka peneliti tertarik melakukan penelitian pengetahuan ibu tentang tumbuh kembang balita dengan partisipasi dalam penimbangan balita di Posyandu Anggrek Kelurahan Popongan Kabupaten Semarang.

Tujuan penelitian ini adalah untuk menganalisa hubungan pengetahuan ibu tentang tumbuh kembang balita dengan partisipasi dalam penimbangan balita di Posyandu Anggrek Kelurahan Popongan Kabupaten Semarang. Manfaat bagi masyarakat bisa memberikan motivasi untuk mengetahui dan memahami tentang tumbuh kembang balita sehingga masyarakat bersedia menimbang balita di posyandu secara teratur.

\section{METODOLOGI PENELITIAN}

Jenis penelitian yang digunakan adalah penelitian korelatif dengan pendekatan cross sectional, yaitu pengukuran variabel terikat dengan variabel bebas dalam waktu yang bersamaan yaitu untuk mencari hubungan antara dua variabel. Penelitian ini terdapat satu variabel bebas yaitu pengetahuan ibu tentang tumbuh kembang balita dan satu variabel terikat yaitu partisipasi ibu dalam penimbangan balita (Notoatmodjo, 2002).

Populasi dalam penelitian ini adalah semua ibu yang mempunyai balita di Posyandu Anggrek Dusun Popongan Kelurahan Popongan Kabupaten
Semarang sebanyak 59 ibu pada bulan Februari 2020. sampel yang didapatkan 37 responden.

Data yang dikumpulkan pada penelitian ini menggunakan kuesioner yang berisi daftar pernyataan tentang pengetahuan ibu mengenai tumbuh kembang dan partisipasi dalam penimbangan balita. Uji validitas untuk mengukur apakah instrumen valid atau tidak. Uji validitas menggunakan korelasi prodct moment. Instrument dikatakan valid jika nilai koparasi positif dan nilai probabilitas korelasi \{sig.(2 tailed) $\}<$ taraf siqnifikan 0,05

Analisis data menggunakan analisa univariat untuk mendiskripsikan karakteristik responden meliputi umur balita, umur ibu, pendidikan ibu, pekerjaan ibu dan mendiskripsikan variable bebas yaitu pengetahuan ibu dan partisipasi. Dan juga menggunakan Analisis Bivariat untuk menganalisis hubungan pengetahuan tentang tmbuh kembang dan partisipasi dalam penimbangan balita. Uji statistik yang digunakan adalah Chi-square dengan nilai $\alpha=0,05$. Pengolahan data menggunakan computer dengan program SPSS for windows versi 23.

Hipotesa pada peneltian ini jika $p<$ 0,05 $\mathrm{Ha}$ diterima maka dinyatakan ada hubungan bermakna antara pengetahuan ibu tentang tumbuh kembang balita dengan partisipasi dalam penimbangan balita di posyandu. Kemudian bila nilai $p \geq$ 0,05 Ho diterima maka dinyatakan tidak 
ada hubungan bermakna antara pengetahuan ibu tentang tumbuh kembang balita dengan partisipasi dalam penimbangan balita di posyandu.

\section{HASIL PENELITIAN DAN BAHASAN}

Berdasarkan hasil penelitian, didapatkan umur balita rata-rata 24,41 dengan nilai median 23,00 . Usia termuda yang menjadi responden penelitian adalah 1 bulan dan usia tertua adalah 60 bulan. umur ibu rata-rata 33,00 dengan nilai median 34,00 . Usia termuda yang menjadi responden penelitian adalah 24 tahun dan usia tertua adalah 51 tahun. Untuk pendidikan ibu dari 37 responden yang terbanyak pendidikan SMA dengan 19 responden $(51,4 \%)$, dan paling sedikit pendidikan Sarjana sebanyak 6 responden (16,2\%). Untuk pekerjaan ibu dari 37 responden yang terbanyak pekerjaan Swasta dengan 17 responden $(45,9 \%)$ dan terkecil pekerjaan Buruh sebanyak 9 responden $(24,3 \%)$

\section{Analisa Univariat}

Distribusi frekuensi berdasarkan pengetahuan tentang tumbuh kembang balita

Tabel 1. Distribusi Frekuensi pengetahuan tentang tumbuh kembang balita

\begin{tabular}{ccc}
\hline Pengetahuan & Frekuensi & $\begin{array}{c}\text { Prosentase } \\
(\%)\end{array}$ \\
\hline Cukup & 3 & 8,1 \\
Baik & 34 & 91,9 \\
\hline Total & 37 & 100,0 \\
\hline
\end{tabular}

Berdasarkan tabel 1. diatas dapat diperoleh bahwa sebagian besar memiliki tingkat pengetahuan dengan kategori baik yaitu sebanyak 34 responden (91,9\%) dan kategori cukup sebanyak 3 responden (8,1\%). Sesuai Notoatmodjo (2012) bahwa, pengetahuan terjadi setelah seseorang melakukan penginderaan terhadap suatu objek melalui panca indera seperti indera penglihatan, pendengaran, penciuman, rasa dan raba. Sebagian besar pengetahuan manusia didapat melalui penglihatan dan pendengaran, selain itu pengetahuan juga dipengaruhi pendidikan. Semakin tinggi pendidikan seseorang maka semakin mudah pula seseorang tersebut menerima informasi yang diberikan. Pengetahuan ibu yang sebagian besar adalah baik karena sebagian besar ibu berpendidikan SMA yaitu sebanyak 19 responden (51,4\%). Tingkat pendidikan yang tinggi menyebabkan ibu lebih mudah menerima informasi baru.

Distribusi frekuensi berdasarkan partisipasi penimbangan

Tabel 2. Distribusi frekuensi berdasarkan partisipasi penimbangan

\begin{tabular}{lcc}
\hline Partisipasi & Frekuensi & $\begin{array}{c}\text { Prosentase } \\
\text { (\%) }\end{array}$ \\
\hline Partisipasi & 27 & 73,0 \\
Tidak & 10 & 27,0 \\
partisipasi & & \\
\hline \multicolumn{1}{c}{ Total } & 37 & 100,0 \\
\hline
\end{tabular}

Berdasarkan tabel. 2 diatas dapat diketahui bahwa sebagian besar responden berpartisipasi dalam 
penimbangan posyandu yaitu sebanyak 27 responden $(73,0 \%)$ dan kategori tidak partisipasi yaitu sebanyak 10 responden (27,0\%). Sesuai Depkes RI (2004), bahwa partisipasi masyarakat umumnya dipandang sebagai suatu bentuk perilaku. Salah satu bentuk perilaku kesehatan adalah partisipasi ibu balita dalam program Posyandu, yang mewujudkan dengan membawa anak mereka untuk ditimbang berat badannya ke Posyandu secara teratur setiap bulan, karena perilaku keluarga sadar gizi (keluarga yang mampu mengenal, mencegah dan mengatasi masalah gizi setiap anggotanya) salah satunya dapat dilihat dari indikator menimbang berat badan balita secara teratur ke Posyandu. Penimbangan balita dikatakan baik apabila minimal ada empat kali anak balita ditimbang ke Posyandu secara berturutturut dalam enam bulan dan dikatakan tidak baik apabila kurang dari empat kali secara berturut-turut ke Posyandu dalam enam bulan.

\section{Analisa Bivariat}

Tabel 3. Hubungan Pengetahuan dan Partisipasi

\begin{tabular}{ccccccc}
\hline $\begin{array}{c}\text { Pengeta } \\
\text { huan }\end{array}$ & \multicolumn{5}{c}{ Partisipasi } \\
\cline { 2 - 6 } & partisi & $\%$ & $\begin{array}{c}\text { Tidak } \\
\text { partisi } \\
\text { pasi }\end{array}$ & $\%$ & $\begin{array}{c}\text { Tot } \\
\text { al }\end{array}$ & \\
\hline Cukup & 2 & 5,4 & 1 & 2,7 & 3 & 8,1 \\
Baik & 25 & 67, & 9 & 24, & 34 & 91,9 \\
& & 6 & & 3 & & \\
\hline Total & 27 & 73 & 10 & 27 & 37 & 100 \\
\hline P value & 0,798 & & & & \\
\hline
\end{tabular}

Berdasarkan tabel 3. Hubungan pengetahuan dan partisipasi dapat diketahui bahwa pengetahuan ibu sebagian besar baik berjumlah 34 responden yang partisipasi dalam penimbangan ke posyandu sebanyak 25 responden (67,6\%) lebih besar dibandingkan dengan yang tidak partisipasi sebanyak 9 responden $(24,3 \%)$, sedangkan untuk pengetahuan cukup berjumlah 3 responden yang partisipasi dalam penimbangan ke posyandu sebanyak 2 responden $(5,4 \%)$ dan yang tidak partisipasi sebanyak 1 responden (2,7\%).

Berdasarkan pengujian statistik dengan menggunakan uji Chi-square didapatkan nilai $p$ value $0,798>0,05$. Berdasarkan hasil tersebut maka dapat dinyatakan bahwa $\mathrm{Ho}$ diterima dan $\mathrm{Ha}$ ditolak maka dinyatakan tidak ada hubungan bermakna antara tingkat pengetahuan ibu tentang tumbuh kembang balita dengan partisipasi ibu dalam penimbangan balita di posyandu. Sesuai pendapat Notoatmodjo (2003), bahwa pengetahuan merupakan salah satu pendukung yang sangat penting untuk meningkatkan peran serta seseorang. Pengetahuan merupakan skematis serta sangat penting dalam membentuk tindakan seseorang. Partisipasi ibu datang ke posyandu memantau pertumbuhan dan perkembangan anak balitanya ditentukan oleh beberapa faktor seperti tingkat pendidikan, pekerjaan, umur, lingkungan, 
dan sosial budaya. (Utami \& Damayanti, 2016). Penelitian Ite Ate Yuviska di Teluk Betung juga menyakan bahwa ada hubungan pengetahuan dan partisipasi ibu. Sehingga hal ini terjadi kesenjangan antara teori dengan hasil penelitian karena pengetahuan tidak berkaitan dengan partisipasi ibu dalam penimbangan balita dan tidak ada hubungan antara pengetahuan dengan partisipasi dikarenakan faktor lain seperti faktor motivasi kunjungan ibu balita ke posyandu dan peran kader dalam memberikan motivasi serta mengajak ibu balita untuk selalu datang ke posyandu setiap bulan sekali agar bisa memantau pertumbuhan dan perkembangan balita. Berdasarkan penelitian Poengky Nouse Asta partisipasi ibu ke posyandu dipengaruhi juga oleh bebrapa faktor antara lain usia, pendidikan, pekerjaan dan penghasilan. Sedangkan dari penelitian Reihana menyatakan bahwa faktor paling dominan yang mempengaruhi partisipasi ibu adalah interaksi pendidikan dan pengetahuan disusul oleh faktor dukungan keluarga, umur balita, motivasi dan pendidikan.

\section{KESIMPULAN}

Dari hasil penelitian dan pembahasan di atas, maka dapat disimpulkan sebagai berikut:

1. Karakteristik responden meliputi; Rata-rata usia balita adalah 24 bulan (5,4\%). Rata-rata umur ibu adalah 33 tahun (5,4\%). Sebagian besar pendidikan ibu adalah lulusan SMA $(51,4 \%)$. Sebagian besar pekerjaan ibu adalah Swasta (45,9\%).

2. Sebagian besar pengetahuan ibu balita adalah dalam kategori baik yaitu 34 responden (91,9\%) dan kategori cukup 3 responden (8,1\%).

3. Sebagian besar partisipasi ibu untuk datang ke posyandu adalah dalam kategori partisipasi yaitu sebanyak 27 responden $(73,0 \%)$ dan yang tidak partisipasi sebanyak 10 responden $(27,0 \%)$.

4. Tidak terdapat hubungan yang bermakna antara hubungan tingkat pengetahuan ibu tentang tumbuh kembang balita dengan partisipasi ibu dalam penimbangan balita di Posyandu Anggrek Kelurahan Popongan Kabupaten Semarang dengan nilai $p$ sebesar 0,798 ( $p>$ 0,05 )

Berdasarkan kesimpulan pada bagian akhir penelitian ini, peneliti menyampaikan saran pada pihak yang terkait tentang pentingnya pengetahuan dengan partisipasi ibu dalam penimbangan balita. Saran yang dapat disampaikan antara lain:

1. Tenaga Kesehatan

Hasil penelitian ini dapat digunakan oleh tenaga kesehatan dalam memberikan asuhan kebidanan tentang pengetahuan ibu balita dengan partisipasi ibu dalam penimbangan balita ke posyandu 
untuk mengenal tumbuh kembang balita.

2. Institusi Pendidikan Institusi khususnya Akademi Kebidanan Abdi Husada Semarang dapat menambah sumber wacana dan referensi tentang pengetahuan ibu mengenai tumbuh kembang balita.

3. Masyarakat

Diharapkan supaya selalu aktif dalam berkunjung ke posyandu agar tumbuh kembang terpantau.

4. Peneliti

Peneliti hendaknya dapat mengembangkan pengetahuan dan referensi bagi peneliti selanjutnya untuk mengungkap faktor-faktor lain yang berhubungan dengan partisipasi penimbangan balita ke posyandu

\section{DAFTAR PUSTAKA}

1. Adriana, Dian. 2013. Tumbuh Kembang \& Terapi Bermain pada Anak. Jakarta :

Salemba Medika.

2. Arali. 2008. Catatan Ringan Tentang Perkembangan Posyandu. Diakses pada 9 Agustus 2020.

3. Arikunto, Suharsimi. 2006. Prosedur Penelitian Suatu Pendekatan Praktik. Jakarta: Rineka Cipta.

4. Bidan, Stasiun. 2003. http://stasiunbidan.blogspot.com/200

9/10/kti-gambaranrendahnya cakupan $/ \mathrm{htm} / ? m=1$. Diakses pada 9 Agustus 2020.

5. Depkes RI. 2004. Tujuan Pembangunan Nasional. Jakarta : Depkes RI.

6. Depkes RI. 2006. Pedoman Umum Pengelolaan Posyandu. Jakarta : Depkes RI.

7. Dinas Kesehatan Provinsi Jawa Tengah. 2007. Profil Kesehatan
Provinsi JawaTengah 2007. Jawa Tengah : Dinkes Provinsi Jawa Tengah.

8. Gaib, Mandola. 2011. http://statistikkesehatan.blogspot.com/2011/10/ujifisherexact.html?m=1. Diakses pada 9 Agustus 2020.

9. Hidayat, A. Aziz Alimul. 2010. Metode Penelitian Teknik Analisa Data. Jakarta :

Salemba Medika.

10. http://repository.poltekkestjk.ac.id/848/4/BAB\%20II.pdf

11. Jurnal kebijakan kesehatan indonesia vol 5 no 2 Juni 2016 Faktor-faktor yang berhubungan dengan tingkat partisipasi ibu balita untuk menimbang balita ke posyandu di wilayah kerja puskesmas panjang Bandar lampung 2010

12. Departemen Pendidikan Nasional. 2008. Kamus Besar Bahasa Indonesia Pusat Bahasa. Jakarta : Gramedia Pustaka Utama.

13. Poengky Nouse Asta, Teuku Samsul Alam. Faktor yang Mempengaruhi Partisipasi ibu dalam Kegiatan Posyandu.http://jim.unsyiah.ac.id/FK ep/article/view/3883

14. Marimbi, Hanum. 2010. Tumbuh Kembang, Status Gizi, dan Imunisasi Dasar pada Balita. Yogyakarta : Nuha Medika.

15. Marzuki. 2003. Metodologi Riset. Yogyakarta : Bagian Penerbitan Fakultas Ekonomi Universitas Islam Indonesia.

16. Notoadmodjo, Soekidjo. 2002. Pengantar Pendidikan Kesehatan. Jakarta : Rineka Cipta.

17. Notoadmodjo, Soekidjo. 2003. Metodologi Penelitian Kesehatan. Jakarta : Rineka Cipta.

18. Notoadmodjo, Soekidjo. 2005. Metodologi Penelitian Kesehatan. Jakarta : Rineka Cipta.

19. Notoadmodjo, Soekidjo. 2010. Promosi Kesehatan Teori dan Aplikasi. Jakarta : Rineka Cipta.

20. Notoadmodjo, Soekidjo. 2012. Promosi Kesehatan dan Perilaku Kesehatan. Jakarta : Rineka Cipta.

21. Nursalam. 2003. Metodologi Penelitian IImu Keperawatan. Jakarta : Salemba Medika. 
22. Septiari, Bety Bea. 2012. Mencetak Balita Cerdas dan Pola Asuh Orang Tua. Yogyakarta : Nuha Medika.

23. Soetjiningsih. $2005 . \quad T u m b u h$ Kembang Anak. Jakarta : EGC.

24. Suhardjo. 2003. Berbagai Cara Pendidikan Gizi. Jakarta : Bumi Aksara.

25. Sugiyono. 2011. Statistika untuk Penelitian. Bandung : Alfabeta.

26. Sulistyawati, Ari. 2014. Deteksi Tumbuh Kembang Anak. Jakarta : Salemba Medika. 